\title{
First experience with the new portable extracorporeal membrane oxygenation system Cardiohelp for severe respiratory failure in adults
}

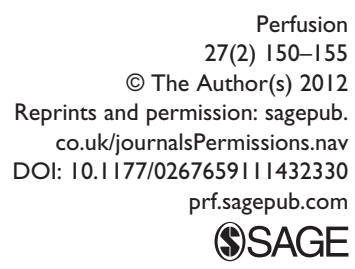

Perfusion

27(2) I50-155

The Author(s) 2012

co.uk/journalsPermissions.nav

@SAGE

\author{
A Haneya', A Philipp', M Foltan', D Camboni', T Müeller'2, \\ T Bein ${ }^{3}$, C Schmid' and M Lubnow ${ }^{2}$
}

\begin{abstract}
Background: Over the last decade, technical improvements in extracorporeal membrane oxygenation (ECMO) equipment have reduced procedure-related complications and have made ECMO an effective option for patients with acute respiratory distress syndrome (ARDS) if conventional therapy fails.

Methods: In this report, we present our early experience with the Cardiohelp, a new portable miniaturized ECMO system, in 22 consecutive patients with ARDS. All patients were placed on venovenous ECMO. Cannulas were inserted percutaneously, employing the Seldinger technique. Data were collected prospectively.

Results: The median patient age was 47 years (36 to 6I). Fifteen patients from regional hospitals were too unstable for conventional transport and were placed on Cardiohelp at the referring hospital and then transported to our institution. The patients were transported by ambulance $(n=2)$ or helicopter $(n=13)$ over a distance of 50-250 km. Cardiohelp support resulted in immediate improvement of gas exchange and highly protective ventilation. The median duration of support was 13 days (8 to 19). An exchange of the device was necessary in 9 patients. Sixteen patients (72.7\%) were successfully weaned from ECMO and fifteen patients (68.2\%) survived. Device-related complications were not observed. Conclusions: The compact portable ECMO device Cardiohelp is a highly effective method to secure vital gas exchange and to reduce further ventilator-induced lung injury in patients with acute respiratory failure. Crucial technical innovations and ease of device transport and implantation allow location-independent stabilization with consecutive inter-hospital transfer.
\end{abstract}

\section{Keywords}

ARDS; ECMO; Cardiohelp

\section{Introduction}

Despite relevant improvements in the treatment of respiratory failure, above all low tidal ventilation, severe acute respiratory distress syndrome (ARDS) continues to have a high mortality rate ${ }^{1}$. The etiology of ARDS can be classified as primary lung insult caused by bacterial, viral, or aspiration pneumonia, or other primary lung disease, or secondary lung injury as a result of shock, trauma, sepsis, or other systemic conditions ${ }^{2}$.

Modern extracorporeal membrane oxygenation (ECMO) currently establishes a place in the treatment of acute severe respiratory failure with presumed improved survival $^{3-5}$. Over the last decade, technical improvements in ECMO equipment, including centrifugal pumps, polymethylpentene (PMP) oxygenators, percutaneous cannulation techniques and heparin-coated circuits, have reduced procedure-related complications ${ }^{4}$. Implantation of ECMO at the referring hospitals and the transport of these patients on ECMO to an institution with expertise is a logistic challenge with a high potential for complications.

\footnotetext{
'Dept. of Cardiothoracic Surgery, University Medical Center Regensburg, Regensburg, Germany

${ }^{2}$ Dept. of Internal Medicine II, University Medical Center Regensburg,

Regensburg, Germany

${ }^{3}$ Dept. of Anesthesiology, University Medical Center Regensburg,

Regensburg, Germany
}

Corresponding author:

Assad Haneya

University Medical Center Regensburg

Department of Cardiothoracic Surgery

Franz-Josef-Strauss-Allee II

D-93053 Regensburg, Germany,

Email: assadhaneya@web.de 
Hence, development of a compact, portable device to support and transport patients with severe respiratory failure is needed.

Recently, the new miniaturized ECMO system Cardiohelp (Maquet Cardiopulmonary, Hirrlingen, Germany) for severe cardiopulmonary failure has been developed and marketed. The small size of this device, with reduced foreign surface combined with BIOLINE coating (Maquet Cardiopulmonary), a plasma resistant membrane and improved pump technology decreases the need for systemic anticoagulation. In clinical practice, an additional advantage of this ECMO system is the integrated sensor technology for measurement of in-line pressures, blood temperature, hemoglobin concentration and venous saturation.

In this report, we present our experience with the new miniaturized system, Cardiohelp, in the first 22 patients with severe respiratory failure.

\section{Patients and Methods}

Between May 2010 and July 2011, we treated 22 ARDS patients with the new system in a veno-venous mode. Twenty patients were supported from the beginning with the Cardiohelp system. Two patients were initially supported with another ECMO system. An exchange of their device was necessary due to circuit thrombus formation. Data collection was performed prospectively.

Before patients were considered potential candidates for ECMO, their clinical course was carefully evaluated. This included optimization of volume status and vasoactive agent requirements, lung protective ventilation with low tidal volumes, moderate hypercapnia, and high positive end-expiratory pressure (PEEP), the use of adjunctive therapeutic measures such as prone position or nitric oxide, as well as treatment of the underlying disease in accordance with standard intensive care procedures ${ }^{6}$.

Patients from regional hospitals who were potential candidates for ECMO were transferred to our center. If the patients were too unstable for conventional transport, they were placed on Cardiohelp at the referring hospital and then transported to our institution. The transport team included a cardiovascular surgeon and/ or an experienced anesthesiologist, a perfusionist and a nurse or paramedic. For ground transport, a special intensive care transport vehicle was used. For air medical transport, a rescue helicopter was available ${ }^{7}$.

The Cardiohelp system (CE licensed for use of 30 days in Europe) consists of a centrifugal pump with an integrated battery for transport and a performance of up to $7 \mathrm{~L} / \mathrm{min}$, a polymethylpentene (PMP) diffusion membrane oxygenator, which avoids plasma leakage and has a total gas exchange surface of $1.8 \mathrm{~m}^{2}$, with a low inherent resistance, and two cannulas. The priming volume of the complete device was $600 \mathrm{~mL}$. An additional advantage of

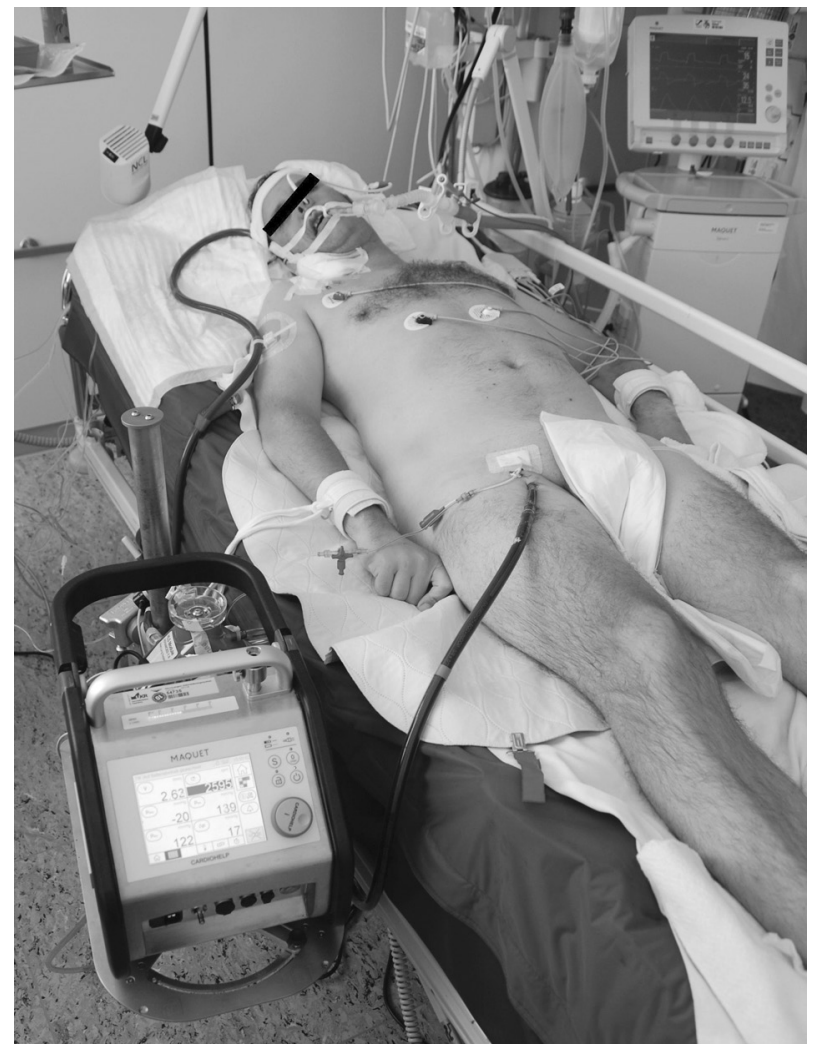

Figure I. Patient on active extracorporeal membrane oxygenation, Cardiohelp. The outflow cannula is inserted in the right femoral vein and advanced into the right internal jugular.

this ECMO system is the integrated sensor technology for measurement of venous oxygen saturation, hemoglobin, hematocrit and arterial blood temperature. Furthermore, the continuous analysis of in- and outflow pressures is displayed (Figure 1). Weighing about $10 \mathrm{~kg}$, the Cardiohelp system can be carried comfortably during transport.

All cannulas were inserted percutaneously, employing the Seldinger technique. For outflow, usually, the right femoral vein was cannulated with a long $21-23$ Fr single-stage cannula (BE-PVS, Maquet Cardiopulmonary). For reinfusion, a short 15 - 17 Fr cannula was used, which was usually implanted in the right internal jugular vein. Six patients were supported using an internal jugular vein insertion of the Avalon Elite bicaval, dual-lumen cannula 25 - 27 Fr (Avalon Laboratories, Rancho Dominguez, CA, USA).

Post-dilatation prior to cannula implantation, all patients received an intravenous single dose of heparin of 1,000-5,000 IU. Systemic anticoagulation was given by continuous infusion of standard heparin. The effect of heparin was measured via the activated partial thromboplastin time (aPTT). As the whole system had a biocompatible BIOLINE coating, a pronounced systemic 
anticoagulation was not necessary and an aPTT 1.5 times normal was considered sufficient (aPTT 50 - 60s). Additionally, $100 \mathrm{mg} /$ day of acetylsalicylic acid were usually given to inhibit platelet aggregation. Oxygen was used as the sweep gas, with a flow of 1-12 L/min.

After implementation of the ECMO, invasiveness of mechanical ventilation was immediately reduced to diminish further ventilator-induced lung injury (VILI). Accordingly, tidal volume, minute ventilation, inspiratory pressure (PIP) and fraction of inspired oxygen $\left(\mathrm{FiO}_{2}\right)$ were decreased (typically $\mathrm{FiO}_{2}<0.5, \mathrm{PIP}<27 \mathrm{~cm}$ $\mathrm{H}_{2} \mathrm{O}$ ). PEEP was not initially reduced to avoid atelectasis due to small tidal volume ${ }^{5}$.

After weaning and removal of the cannulas, hemostasis was achieved with manual compression of the groin and neck.

\section{Statistical analysis}

The statistical analysis was performed using the SPSS 18.0 software (SPSS, Chicago, IL, U.S.A.). Normal distribution was assessed by the Lilliefors Modification of the Kolmogorov-Smirnov test. Values of continuous data are presented as mean \pm standard deviation (SD) or as the median, with interquartile range when appropriate. Statistical significance was considered when $\mathrm{p}<0.05$.

\section{Results}

A total of 22 patients with severe acute respiratory failure were treated with the new miniaturized device, Cardiohelp (Table 1). The cohort consisted of 4 women and 18 men, with a median age of 47 years (36 to 61). Causes of severe respiratory failure were: pneumonia in 14 patients, multiple trauma or post-surgery in 5 patients, and influenza A (H1N1) infection in 3 patients. The median Sequential Organ Failure Assessment (SOFA) score was 9 (7 to 13) and the median Lung Injury Score (LIS) was 3.50 (3.33 to 3.67). Seven patients were successfully supported with Cardiohelp at our center. Fifteen patients from regional hospitals were too unstable for conventional transport, and were placed on ECMO at the referring hospital and then transported to our institution. The median duration of ventilation before ECMO was 1 day (1 to 3). One patient was non-invasively ventilated without mechanical ventilation; the ECMO was implanted to avoid invasive ventilation after a post-pneumonectomy bronchopleural fistula. Sixteen patients were cannulated by the conventional technique (right femoral vein to right internal jugular or right subclavian vein). Six patients were supported using internal jugular vein insertion of the newly developed Avalon Elite bicaval dual-lumen cannula.

Table 3 summarizes changes in arterial blood gases, arterial $\mathrm{pH}$, inotropic support, and mean arterial pressure over time. Arterial blood gas analyses prior to
Table I. Patient data and characteristics before ECMO support

\begin{tabular}{lc}
\hline & $\mathrm{n}=22$ \\
\hline Age, years & $47(36$ to $6 \mathrm{I})$ \\
Male (\%) & $18(8 \mathrm{I} .8)$ \\
BMI, kg/m² & $3 \mathrm{I} \pm 8$ \\
Diagnosis leading to ARDS (\%) & \\
$\quad$ Pneumonia & $14(63.6)$ \\
Trauma/Post-surgery & $5(22.7)$ \\
HINI & $3(13.7)$ \\
SOFA score & $9(7$ to I3) \\
LIS score & $3.5(3.33$ to 3.67$)$ \\
Mechanical ventilation, days & $I(I$ to 3$)$ \\
Acute renal failure (\%) & $3(\mid 3.7)$
\end{tabular}

ARDS = acute respiratory distress syndrome; $\mathrm{ECMO}=$ extracorporeal membrane oxygenation; $\mathrm{HINI}=$ Influenza $\mathrm{A}$ infection; LIS = lung injury score; $\mathrm{SOFA}=$ sequential organ failure assessment score

Table 2. Overview of ECMO and patient outcome

\begin{tabular}{lc}
\hline & $\mathrm{n}=22$ \\
\hline Transport on ECMO (\%) & $15(68.2)$ \\
ECMO duration, days & $13(8$ to I9) \\
Ventilation after ECMO, days & 6 (3 to II) \\
Weaning (\%) & $16(72.7)$ \\
Survival (\%) & $15(68.2)$ \\
Blood transfusion & $13(59.1)$ \\
Device exchange & $9(40.9)$ \\
Device-related complications (\%) & $0(0)$ \\
\hline
\end{tabular}

ECMO = extracorporeal membrane oxygenation

implantation revealed a $\mathrm{PaO}_{2} / \mathrm{FiO}_{2}$ ratio of $60 \mathrm{mmHg}$ (46 to 75 ), a $\mathrm{PaCO}_{2}$ of $67 \mathrm{mmHg}$ (57 to 100) and a $\mathrm{pH}$ level of 7.23 (7.17 to 7.32). Two hours after implantation, the $\mathrm{PaO}_{2} / \mathrm{FiO}_{2}$ ratio, $\mathrm{PaCO}_{2}$ and $\mathrm{pH}$ levels had significantly improved to $123 \mathrm{mmHg}$ (94 to 156 ), $34 \mathrm{mmHg}$ (31 to 39) and 7.49 (7.41 to 7.54) $(\mathrm{p}<0.05)$. Also, the mean arterial pressure (MAP) increased from $69 \mathrm{mmHg}$ (63 to 77$)$ to $79 \mathrm{mmHg}(72$ to 89$)(\mathrm{p}<0.05)$, despite a notable reduction in the norepinephrine dose from 1.5 $\mathrm{mg} / \mathrm{h}(0.4$ to 4.3$)$ to $1 \mathrm{mg} / \mathrm{h}(0.4$ to 3.2$)$ ( $\mathrm{p}<0.05)$. Blood flow through the device averaged $3.1 \mathrm{~L} / \mathrm{min}$ (2.7 to 3.4 ) initially. After implementation of the Cardiohelp, the ventilation parameters (tidal volume, PIP and $\mathrm{FiO}_{2}$ ) could be significantly reduced towards more protective ventilation.

The median duration of support was 13 days ( 8 to 19 ). Four patients on ECMO were successfully weaned from mechanical ventilation. After weaning, the median duration of continued ventilation was 6 days ( 3 to 11). Sixteen patients were successfully weaned from ECMO and fifteen patients (68.2\%) survived. Six patients died of multiple organ failure and sepsis while on ECMO. One patient died of multiple organ failure 49 days after weaning. 
Table 3. Changes in blood gases, hemodynamics and laboratory variables.

\begin{tabular}{|c|c|c|c|c|c|c|}
\hline & $\begin{array}{l}\text { pre ECMO } \\
(n=22)\end{array}$ & $\begin{array}{l}2 \text { hours } \\
(n=22)\end{array}$ & $\begin{array}{l}\text { Day I } \\
(n=22)\end{array}$ & $\begin{array}{l}\text { Day } 2 \\
(n=22)\end{array}$ & $\begin{array}{l}\text { End of ECMO } \\
(n=16)\end{array}$ & $\begin{array}{l}\text { Day I after ECMO } \\
(\mathrm{n}=\mathrm{I} 6)\end{array}$ \\
\hline $\begin{array}{l}\mathrm{PaO}_{2} / \mathrm{FiO}_{2} \\
(\mathrm{mmHg})\end{array}$ & $\begin{array}{l}60 \\
(46 \text { to } 75)\end{array}$ & $\begin{array}{l}123^{*} \\
\text { ( } 94 \text { to I56) }\end{array}$ & $\begin{array}{l}153^{*} \\
(102 \text { to } 220)\end{array}$ & $\begin{array}{l}158^{*} \\
\text { (126 to } 195)\end{array}$ & $\begin{array}{l}265^{*} \\
(215 \text { to } 318)\end{array}$ & $\begin{array}{l}230 * \\
\text { (160 to } 274)\end{array}$ \\
\hline $\begin{array}{l}\mathrm{PaCO}_{2} \\
(\mathrm{mmHg})\end{array}$ & $\begin{array}{l}67 \\
\text { (57 to } 100)\end{array}$ & $\begin{array}{l}34^{*} \\
(31 \text { to } 39)\end{array}$ & $\begin{array}{l}37^{*} \\
\text { (35 to } 43 \text { ) }\end{array}$ & $\begin{array}{l}43 * \\
(39 \text { to } 45)\end{array}$ & $\begin{array}{l}42^{*} \\
(37 \text { to } 42)\end{array}$ & $\begin{array}{l}4 I^{*} \\
(37 \text { to } 50)\end{array}$ \\
\hline $\mathrm{pH}$ & $\begin{array}{l}7.23 \\
\text { (7.17 to } 7.32)\end{array}$ & $\begin{array}{l}7.49 * \\
(7.4 \mid \text { to } 7.54)\end{array}$ & $\begin{array}{l}7.48^{*} \\
\text { ( } 7.43 \text { to } 7.49)\end{array}$ & $\begin{array}{l}7.44^{*} \\
\text { ( } 7.43 \text { to } 7.45)\end{array}$ & $\begin{array}{l}7.42^{*} \\
\text { (7.39 to } 7.49)\end{array}$ & $\begin{array}{l}7.43^{*} \\
(7.35 \text { to } 7.44)\end{array}$ \\
\hline MAP $(\mathrm{mmHg})$ & $\begin{array}{l}69 \\
(63 \text { to } 77)\end{array}$ & $\begin{array}{l}79 * \\
\text { (72 to } 89)\end{array}$ & $\begin{array}{l}78^{*} \\
\text { (67 to } 83)\end{array}$ & $\begin{array}{l}8 I^{*} \\
(76 \text { to } 85)\end{array}$ & $\begin{array}{l}88^{*} \\
(76 \text { to } 95)\end{array}$ & $\begin{array}{l}8 I^{*} \\
(72 \text { to } 86)\end{array}$ \\
\hline $\begin{array}{l}\text { Norepinephrine } \\
(\mathrm{mg} / \mathrm{h})\end{array}$ & $\begin{array}{l}1.5 \\
(0.4 \text { to } 4.3)\end{array}$ & $\begin{array}{l}1.0 * \\
(0.4 \text { to } 3.2)\end{array}$ & $\begin{array}{l}0.7^{*} \\
(0.3 \text { to } 1.2)\end{array}$ & $\begin{array}{l}0.2 * \\
(0.0 \text { to } 0.6)\end{array}$ & $\begin{array}{l}0.0 * \\
(0.0 \text { to } 0.0)\end{array}$ & $\begin{array}{l}0.0 * \\
(0.0 \text { to } 0.0)\end{array}$ \\
\hline $\begin{array}{l}\text { ECMO flow } \\
\text { (L/min) }\end{array}$ & - & $\begin{array}{l}3.1 \\
(2.7 \text { to } 3.4)\end{array}$ & $\begin{array}{l}2.7 \\
(2.5 \text { to } 3.1)\end{array}$ & $\begin{array}{l}2.6 \\
(2.4 \text { to } 2.9)\end{array}$ & $\begin{array}{l}1.5 \\
(1.4 \text { to } 1.6)\end{array}$ & - \\
\hline $\begin{array}{l}\text { Hemoglobin } \\
\text { (g/dL) }\end{array}$ & $\begin{array}{l}\text { II.I } \\
(9.1 \text { to } 12.3)\end{array}$ & $\begin{array}{l}10.3 \\
(9.4 \text { to } 11.3)\end{array}$ & $\begin{array}{l}9.9 * \\
(9.2 \text { to } 10.9)\end{array}$ & $\begin{array}{l}9.5^{*} \\
(9.0 \text { to } 10.1)\end{array}$ & $\begin{array}{l}8.7^{*} \\
(8.1 \text { to } 9.2)\end{array}$ & $\begin{array}{l}9.2^{*} \\
(8.1 \text { to } 9.6)\end{array}$ \\
\hline $\begin{array}{l}\text { Free Hb } \\
(\mathrm{mg} / \mathrm{L})\end{array}$ & $\begin{array}{l}39 \\
\text { (30 to } 163 \text { ) }\end{array}$ & $\begin{array}{l}40 \\
(30 \text { to I23) }\end{array}$ & $\begin{array}{l}54 \\
\text { (31 to } 91)\end{array}$ & $\begin{array}{l}52 \\
\text { (31 to } 72)\end{array}$ & $\begin{array}{l}58 \\
\text { (34 to } 102)\end{array}$ & $\begin{array}{l}48 \\
\text { (30 to } 83)\end{array}$ \\
\hline $\begin{array}{l}\text { Platelets } \\
(/ \mathrm{nL})\end{array}$ & $\begin{array}{l}207 \\
\text { (108 to 298) }\end{array}$ & $\begin{array}{l}175 \\
\text { (86 to } 277)\end{array}$ & $\begin{array}{l}159 * \\
\text { (86 to } 243)\end{array}$ & $\begin{array}{l}127^{*} \\
(91 \text { to } 235)\end{array}$ & $\begin{array}{l}119 * \\
\text { (99 to } 166)\end{array}$ & $\begin{array}{l}123 * \\
\text { (102 to } 182 \text { ) }\end{array}$ \\
\hline $\begin{array}{l}\text { Lactic acid } \\
(\mathrm{mg} / \mathrm{dL})\end{array}$ & $\begin{array}{l}23 \\
(15 \text { to } 36)\end{array}$ & $\begin{array}{l}30 \\
(16 \text { to } 49)\end{array}$ & $\begin{array}{l}20 \\
(16 \text { to } 30)\end{array}$ & $\begin{array}{l}16 * \\
(12 \text { to } 24)\end{array}$ & $\begin{array}{l}11 * \\
(9 \text { to } 17)\end{array}$ & $\begin{array}{l}11 * \\
\text { (7 to } 12)\end{array}$ \\
\hline
\end{tabular}

$*=p<0.05$ to first measurement; ECMO = extracorporeal membrane oxygenation; $\mathrm{FiO}_{2}=$ fraction of inspired oxygen; $\mathrm{Hb}=$ hemoglobin;

$\mathrm{MAP}=$ mean arterial pressure; $\mathrm{PaCO}_{2}=$ partial pressure of carbon dioxide in arterial blood; $\mathrm{PaO} \mathrm{O}_{2}=\mathrm{Partial}$ pressure of oxygen in arterial blood

Acute renal failure during support was observed in three patients and two of these patients died on ECMO.

Laboratory values before, during and after ECMO support are presented in Table 3. Hemoglobin levels and platelet counts dropped during ECMO support $(\mathrm{p}<0.05)$. The plasma free hemoglobin level as a marker of hemolysis was not significantly altered by ECMO (Table 3 ). Thirteen patients required red blood cell (RBC) transfusion during Cardiohelp support. Transfusion requirements averaged 0.3 units ( 0.1 to 0.4$)$ of RBC per day. Five patients required platelet transfusion and only three patients required fresh frozen plasma (FFP) transfusion.

Technical problems that could not be controlled or other device-related complications with an adverse effect on outcome were not observed. On-line measurement failed in 5 patients after $3-7$ days. An exchange of the device was necessary in 9 patients due to circuit thrombus formation, which results in an average device time of $9 \pm 5$ days (Figure 2). Although aPTT was between 50 and $60 \mathrm{sec}$, which was the target level, the flow resistance increased significantly at $3.0 \mathrm{~L} / \mathrm{min}$. Membrane oxygenator $(\mathrm{MO})$ replacement criteria were the appearance of reduced $\mathrm{CO}_{2}$ elimination and oxygenation transfer capacity, which were considered to be the consequence of thrombotic deposits on the gas exchange capillaries. A further criterion was an increase in blood flow resistance with a pressure decline $(\mathrm{dpMO}=\mathrm{pMO}$ in $-\mathrm{pMO}$ out $)$ across the $\mathrm{MO}$ of more than $70 \mathrm{mmHg}$ at a blood flow of
$3 \mathrm{~L} / \mathrm{min}$, indicating the necessity for replacement of the device ${ }^{8}$.

Infections associated with the system and/or cannulas were not observed. As the reason of acute deterioration in most patients was an infectious complication, all patients had been on broad-spectrum antibiotic treatment prior to support.

\section{Comment}

Despite improvements in ventilation support techniques, lung protection strategies and the application of new support treatment, ARDS continues to have a high mortality rate ${ }^{1}$. ECMO is accepted as a standard-of-care for neonates and children with progressive respiratory and/or cardiac failure refractory to conventional management ${ }^{9}$. In contrast, adult ECMO was confined to specialized centers and reserved for exceptional cases due to high complication rates (bleeding, thrombosis, hemolysis, severe infection, and renal insufficiency), increased cost and logistics, but also because of disappointing results from historic randomized trials ${ }^{10,11}$.

Meanwhile, several technical improvements have occurred. The first important technical advance was the development of a new generation of centrifugal pumps. In comparison with traditional roller pumps, the centrifugal pump has virtually no risk of tubing rupture or spallation; it has a smaller priming volume, it does not 


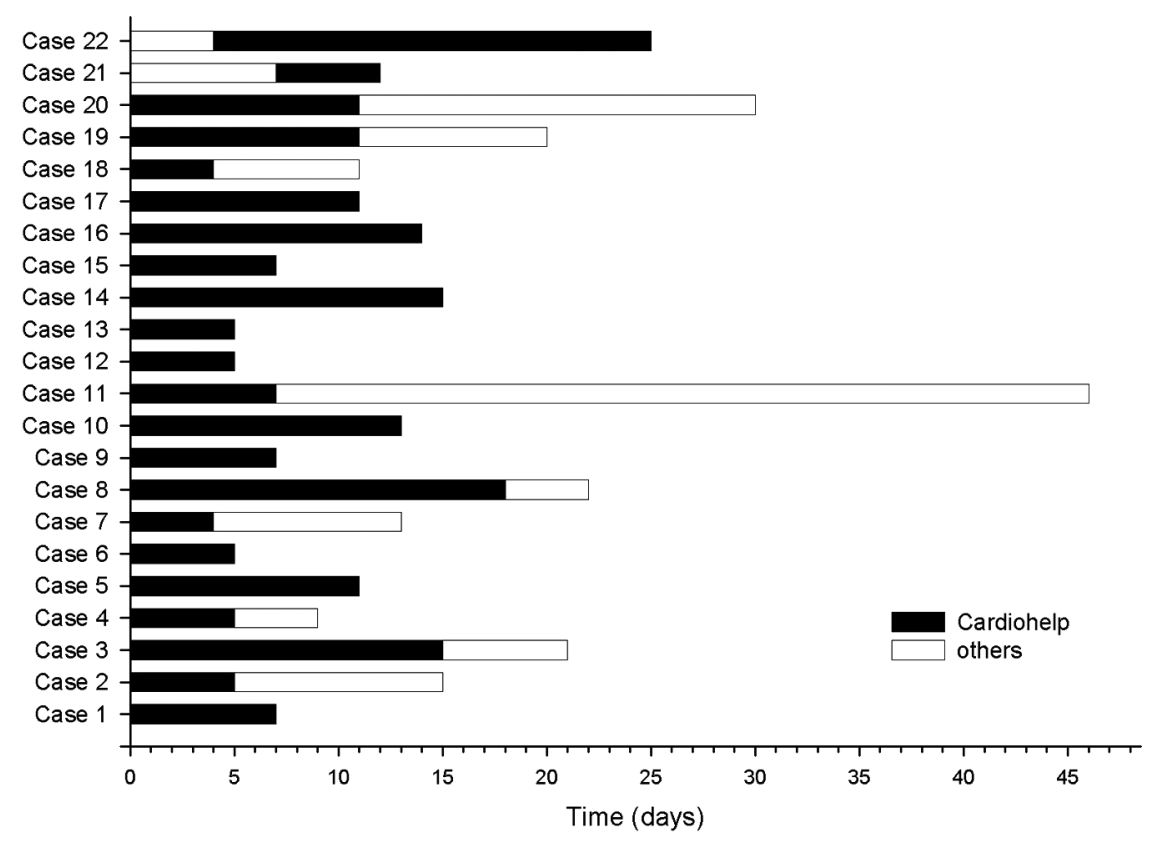

Figure 2. Overview of Cardiohelp exchange rate.

require the use of a reservoir, and it has an equivalent low incidence of hemolysis ${ }^{12}$. The introduction of heparincoated circuits has led to reduced platelet activation, reduced complement activation, reduced granulocyte activation, and greatly reduced heparin requirements ${ }^{13}$. In contrast to silicone membrane oxygenators, the polymethylpentene oxygenator has reduced red blood cell and platelet transfusion requirements, better gas exchange, lower resistance, lower priming volume and an incorporated heat exchanger. In comparison to polypropylene microporous oxygenators, the PMP oxygenator has a reduced rate of oxygenator failure ${ }^{14}$.

In this report, we present our early experience with the new portable miniaturized ECMO system, Cardiohelp, for severe respiratory failure in adults. Implantation of the device led to a rapid and sustained improvement of blood gases and a correction of respiratory acidosis with hemodynamic stabilisation. Our data are of particular interest because $68 \%$ of the patients were successfully weaned and survived, and also because the typical complications related to ECMO support, such as bleeding, thrombosis, and severe infection, were very limited, despite a high SOFA score and long support duration (up to 46 days) ${ }^{4,5}$. With the new device, we did not encounter mechanical complications that were life threatening. In particular, rupture of the tubing or leakage of the oxygenator did not occur. Oxygenator failure was exclusively a result of slowly progressing thrombotic occlusion. An exchange of the device was necessary in 9 patients due to circuit thrombus formation, which resulted in an average device time of 9 days. Mueller et al. demonstrated similar results with another miniaturized
ECMO system ${ }^{5}$. As the whole system has a biocompatible BIOLINE coating, a pronounced systemic anticoagulation was unnecessary without any thromboembolic complications. This decreased the rate of blood transfusions, which had been considerably higher in previous studies, despite the fact that the current study included patients with multiple trauma and thrombocytopenia $^{15,16}$. The rate of hemorrhagic complications was markedly reduced, which makes its implementation possible in patients with a risk of bleeding, which had been traditionally contraindications for ECMO therapy. The plasma free hemoglobin level as a marker of hemolysis was not significantly altered by ECMO.

Patients from regional hospitals who were potential candidates for ECMO were transferred to our center. If the patients were too unstable for conventional transport, they were placed on Cardiohelp at the referring hospital and then transported to our institution. The Cardiohelp system is light enough to be carried by one person and compact enough for transport in a helicopter or vehicle. The integrated rechargeable battery provides 90 minutes of operation without an external power supply. In its most complete configuration, the Cardiohelp permits monitoring of all important blood parameters during support for cardiac and/or respiratory assistance. Thus, the portable system assumes the function of the heart and/or lungs, ensuring that the patient receives adequate oxygen and has a stable circulation during inter- and intra-hospital transport. Complexity and hazards of inter- and intra-hospital transfer could be reduced with the Cardiohelp system.

However, the Cardiohelp device has some disadvantages. The device cost is relatively high compared to other 
ECMO system. The exchange of faulty components (oxygenator or blood pump) is not possible and an exchange of the complete unit is necessary. During longterm support, on-line measurement failed in some cases after a few days.

Our report has a few limitations. The report is a single-center experience, the patient sample is low and a comparison with other devices is lacking.

In conclusion, Cardiohelp is also an effective, compact ECMO device in acute respiratory failure of adults. It helps to secure vital gas exchange and to reduce further ventilator-induced lung injury. Due to its design, monitoring and transport of ECMO patients is facilitated.

\section{Funding}

This research received no specific grant from any funding agency in the public, commercial, or not-for-profit sectors.

\section{Conflict of Interest Statement}

Thomas Müller has received lecture honoraria from Maquet CardioPulmonary Care, Germany. Alois Philipp is Chief Perfusionist at the University Medical Center Regensburg and a member of the technical advisory board of Maquet Cardiopulmonary Care. All of the other authors have no conflict of interest to declare.

\section{References}

1. Rubenfeld GD, Herridge MS. Epidemiology and outcomes of acute lung injury. Chest 2007; 131: 554-562.

2. Udobi KF, Childs E, Touijer K. Acute respiratory distress syndrome. Am Fam Physician 2003; 67: 315-322.

3. Hemmila MR, Rowe SA, Boules TN, et al. Extracorporeal life support for severe acute respiratory distress syndrome in adults. Ann Surg 2004; 240: 595-605.

4. Peek GJ, Mugford M, Tiruvoipati R, et al. Efficacy and economic assessment of conventional ventilatory support versus extracorporeal membrane oxygenation for severe adult respiratory failure (CESAR): a multicentre randomised controlled trial. Lancet 2009; 374: 1351-1363.

5. Müller T, Philipp A, Luchner A, et al. A new miniaturized system for extracorporeal membrane oxygenation in adult respiratory failure. Crit Care 2009; 13(6): R205.
6. Guérin C. Ventilation in the prone position in patients with acute lung injury/acute respiratory distress syndrome. Curr Opin Crit Care 2006; 12: 50-54.

7. Haneya A, Philipp A, Foltan M, et al. Extracorporeal circulatory systems in the interhospital transfer of critically ill patients: experience of a single institution. Ann Saudi Med 2009; 29: 110-114.

8. Lehle K, Philipp A, Gleich O, et al. Efficiency in extracorporeal membrane oxygenation-cellular deposits on polymethylpentene membranes increase resistance to blood flow and reduce gas exchange capacity. ASAIO J 2008; 54: 612-617.

9. Lequier L. Extracorporeal life support in pediatric and neonatal critical care: a review. J Intensive Care Med 2004; 19: 243-258.

10. Zapol WM, Snider MT, Hill JD, et al. Extracorporeal membrane oxygenation in severe acute respiratory failure. A randomized prospective study. JAMA 1979; 242: 2193-2196.

11. Morris AH, Wallace CJ, Menlove RL, et al. Randomized clinical trial of pressure-controlled inverse ratio ventilation and extracorporeal $\mathrm{CO}_{2}$ removal for adult respiratory distress syndrome. Am J Respir Crit Care Med 1994; 149: 295-305.

12. Khoshbin E, Roberts N, Harvey C, et al. Poly-methyl pentene oxygenators have improved gas exchange capability and reduced transfusion requirements in adult extracorporeal membrane oxygenation. ASAIO J 2005; 51:281-287.

13. Moen O, Fosse E, Dregelid E, et al. Centrifugal pump and heparin coating improves cardiopulmonary bypass compatibility. Ann Thorac Surg 1996; 62: 1134-1140.

14. Lawson DS, Ing R, Cheifetz IM, et al. Hemolytic characteristics of three commercially available centrifugal blood pumps. Pediatr Crit Care Med 2005; 6: 573-577.

15. Butch SH, Knafl P, Oberman HA, Bartlett RH. Blood utilization in adult patients undergoing extracorporeal membrane oxygenated therapy. Transfusion 1996; 36: 61-63.

16. Ang AL, Teo D, Lim CH, Leou KK, Tien SL, Koh MB. Blood transfusion requirements and independent predictors of increased transfusion requirements among adult patients on extracorporeal membrane oxygenation - a single centre experience. Vox Sang 2009; 96: 34-43. 